Wahyu Dwi Fintarto dan Moch. Shofwan : Dampak Risiko Pembangunan Mall Tunjungan Plaza Terhadap Keseimbangan Tata Guna Lahan

\title{
DAMPAK RISIKO PEMBANGUNAN MALL TUNJUNGAN PLAZA TERHADAP KESEIMBANGAN TATAGUNA LAHAN
}

\author{
Wahyu Dwi Fintarto ${ }^{1)}$ dan Moch. Shofwan ${ }^{2)}$ \\ ${ }^{12)}$ Program Studi Perencanaan Wilayah dan Kota, Universitas PGRI Adi Buana Surabaya \\ Email : dwi29081996@gmail.com
}

\begin{abstract}
Abstrak
Tunjungan Plaza didirikan pada tahun 1986, mempunyai 6 bangunan utama yang saling berhubungan (Tunjungan Plaza I - VI). Berdasarkan Peraturan Daerah Kota Surabaya No. 12 Tahun 2014 tentang Rencana Tata Ruang Wilayah Kota Surabaya Tahun 2014-2034, Kecamatan Tegalsari termasuk Unit Pengembangan VI Tunjungan dengan fungsi pengembangan perdagangan dan jasa skala internasional dan nasional. Tujuan penelitian adalah menganalisis dampak risiko keberadaan pembangunan Mall Tunjungan Plaza terhadap perkembangan keseimbangan tata guna lahan dari Tahun 1980 sampai Tahun 2018. Penelitian ini menggunakan metode pendekatan deskriptif kuantitatif dengan teknik analisis aritmatik overlay dan uji T. Hasil dari penelitian ini dapat disimpulkan bahwa tidak ada dampak risiko pengaruh yang signifikan, antara hasil data perkembangan penggunanaan lahan Tahun 1980 sampai dengan Tahun 2018, sebelum dan sesudah berdirinya kawasan Mall Tunjungan Plaza terhadap ruang permukiman di Kelurahan Kedungdoro Kota Surabaya.
\end{abstract}

Kata Kunci : Kelurahan Kedungdoro, Mall Tunjungan Plaza, Tata Guna Lahan.

\section{Abstract}

Tunjungan Plaza was established in 1986, has 6 main interconnected buildings (Tunjungan Plaza I - VI). Based on Surabaya City Regulation No. 12 of 2014 concerning Surabaya City Spatial Planning for 2014-2034, Tegalsari District including Tunjungan Development Unit VI with the function of developing international and national trade and services. The research objective was to analyze the risk impact of the existence of Tunjungan Plaza Mall development on the development of land use balance from 1980 to 2018. This study used a quantitative descriptive approach with overlay arithmetic and T-test techniques. The results of this study concluded that there was no impact the risk of significant influence, between the results of data on the development of land use in 1980 up to 2018, before and after the establishment of the Tunjungan Plaza Mall area towards residential space in Kedungdoro Urban Village, Surabaya City.

Keywords : Kedungdoro Village, Tunjungan Plaza Mall, Land Use.

\section{PENDAHULUAN}

Tunjungan Plaza mempunyai luas 5,93 Ha dan memiliki 6 bangunan inti. Kios yang ada di dalam Mall Tunjungan Plaza berjumlah 198 kios, diantara lain Tunjungan 1 terdapat A\&W Restaurants, Burger King, Matahari dan Gramedia. Tunjungan 2 terdapat Stores Sport dan Gerai Makanan terkemuka. Tunjungan 3 terdapat Resort berkelas (fine dining), Matahari, dan Uniqlo. Tunjungan 4 terdapat Shopper dan penggiat kuliner serta Sogo Department Store.
Tunjungan 5 terdapat kios brand-brand seperti Nike, Under Armour, Starbucks Cofee dan The Duck King. Pusat perbelanjaan Tunjungan 6 tidak jauh beda dengan Tunjungan 5 tetapi tunjungan 6 ini diisi oleh brand-brand fast fashion seperti H\&M, Bershka, Pull\&Bear, dan Stradivarius (Jacon, 2017).

Berdasarkan data dari Kecamatan Tegalsari dalam angka 2017, Kelurahan Kedungdoro mempunyai luas $0,74 \mathrm{Km}^{2}$ dan memiliki ketinggian 1,7 meter dari atas permukaan air laut. Kepadatan penduduk 2017 dengan jumlah 34.145 
Jiwa/Km² dengan sebagian besar ( $72 \%$ ) bekerja di sektor industri makanan dan minuman dengan jumlah 372 jiwa. Sarana prasarana Kelurahan Kedungdoro tahun 2017 berupa tempat peribadatan, pendidikan, kesehatan. Sarana prasarana peribadatan terbagi atas 9 Masjid, 17 langgar/surau, 3 Greja protestan dan 2 Wihara. Sarana Prasarana Pendidikan di bagi atas SD 36, SLTP 11, SMA 3, SMK 1. Sarana prasarana kesehatan dibagi atas 1 Puskesmas Kelurahan dan 34 Posyandu (Anonim, 2016).

Berdasarkan Peraturan Daerah Kota Surabaya No. 12 Tahun 2014 tentang Rencana Tata Ruang Wilayah Kota Surabaya Tahun 20142034, Kecamatan Tegalsari termasuk Unit Pengembangan VI Tunjungan dengan fungsi pengembangan perdagangan dan jasa sekala internasional dan nasional, Kawasan Tunjungan Plaza adalah bagian dari Unit Pembangunan VI (Tunjungan) yang berfungsi sebagai tempat permukiman, pemerintaham dan perdangan dan jasa. UP VI di bagi atas 4 kecamatan yaitu Kecamatan Simokerto, Bubutan, Genteng, Tegalsari dan ke empat kecamatan ini disebut dengan Kawasan segi empat emas Tunjungan dan sekitarnya. Sebagai Kawasan pusat perdangangan dan perkantoran, Kawasan segi empat emas Tunjungan memerlukan penanganan dan pengelolaan yang optimal untuk mendukung percepatan pertumbuhan ekonomi Kota Surabaya.

Tujuan dalam artikel ini yaitu untuk menganalisis dampak risiko pengaruh keberadaan pembangunan Mall Tunjungan Plaza terhadap perkembangan keseimbangan tata guna lahan dari Tahun 1980 sampai Tahun 2018. Adapun batas administrasi wilayah dapat dilihat pada Gambar 1. :

Sebelah Utara : Kelurahan Genteng, Kecamatan Genteng Sebelah Timur

Sebelah Barat Kecamatan Sawahan Sebelah Selatan Kecamatan Tegalsari
: Kelurahan Tegalsari, Kecamatan Tegalsari dan Kelurahan Embong Kaliasin, Kecamatan Genteng

: Kelurahan Sawahan, : Kelurahan Wonorejo,

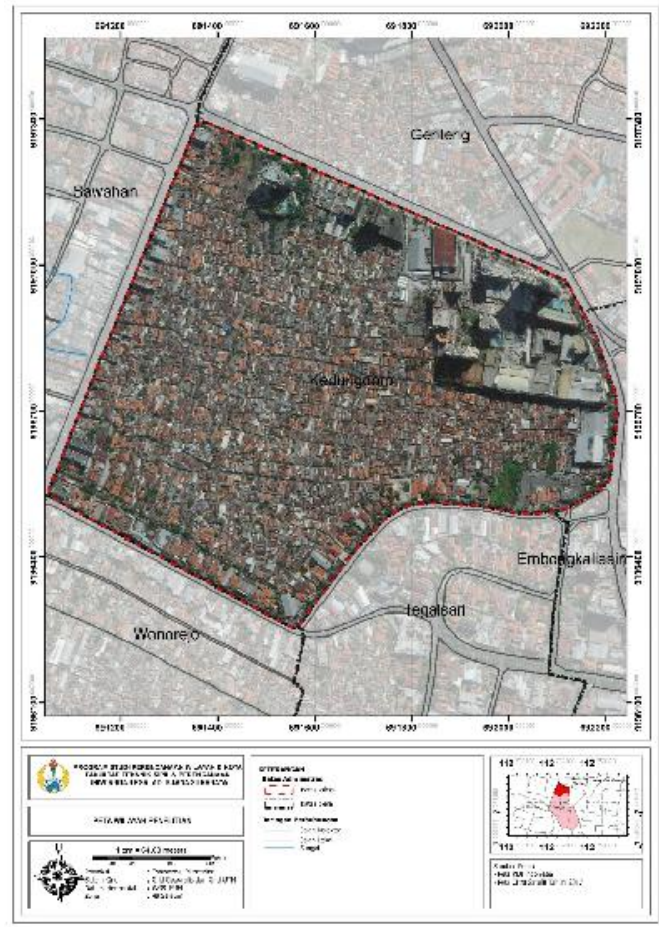

Gambar 1. Peta Administrasi Kelurahan Kedungdoro 


\section{METODOLOGI}

\section{1) Pengumpulan Kebutuhan Data}

Metode pengumpulan data merupakan salah satu prosedur untuk mendapatkan kondisi riil pada suatu penelitian. Pada tahap pengumpulan data dilakukan pemahaman terhadap karakteristik dari variabel yang akan diamati pada wilayah studi. Metode pengumpulan data ditinjau dari berbagai sumber data, yaitu:

1. Dokumentasi

Dokumentasi adalah informasi yang berasal dari catatan penting baik dari Lembaga atau organisasi maupun dari perorangan (Sugiono, 2013). Data yang akan di cari melalui survei dokumentasi adalah foto-foto Kelurahan Kedungdoro Tahun 2018.

2. Literatur

Metode literatur adalah metode pengumpulan data yang dilakukan dengan cara mengambil data - data yang diperlukan dari penelitian-penelitian terdahulu yang berkaitan. Sasaran penelitian-penelitian terdahulu dan instansi seperti LAPAN. Data yang di cari adalah penggunaan lahan Tahun 1980-2018.

\section{2) Teknik Analisis Data}

Teknik analisis yang di gunakan pada penelitian ini menggunakan metode analisis deskriptif kuantitatif dengan menggunakan $U j i$ Paired Sample T-Test Dengan SPSS Statistics 23 For Windows.

$$
t=\frac{\overline{X_{1}}-\overline{X_{2}}}{\sqrt{\frac{s_{1}{ }^{2}}{n_{1}}+\frac{s_{2}{ }^{2}}{n_{2}}-2 r\left(\frac{s_{1}}{\sqrt{n_{1}}}\right)\left(\frac{s_{2}}{\sqrt{n_{2}}}\right)}}
$$

Dimana

$\mathrm{X}_{1}=$ Rata - rata sampel sebelum pembangunan Mall

$\mathrm{X}_{2}=$ Rata - rata sampel sesudah pembangunan Mall

$\mathrm{S}_{1}=$ Simpangan baku sebelum pembangunan Mall

$\mathrm{S}_{2}=$ Simpangan baku sesudah pembangunan Mall

$\mathrm{n}_{1}=$ Jumlah sampel sebelum pembangunan Mall

$\mathrm{n}_{2}=$ Jumlah sampel sesudah pembangunan Mall
Langkah - langkah dalam menganalisis Paired T Test (Muhson, 2012), yaitu:

a. Rekam data hasil analisis perkembangan tata guna lahan dalam dua kolom:

1) Kolom pertama data tentang luas tata guna lahan sebelum pembangunan Mall.

2) Kolom kedua data tentang luas tata guna lahan sesudah pembangunan Mall.

b. Memberi keterangan data tersebut dengan menggunakan variabel view.

1) Baris pertama (Name $=\mathrm{X} 1$, Label = luas tata guna lahan sebelum pembangunan)

2) Baris kedua $($ Name $=\mathrm{X} 2$, Label $=$ luas tata guna lahan sesudah pembangunan)

c. Simpan data tersebut.

d. Melakukan analisis dengan menggunakan menu Analyze Compare Means Paired Samples t test.

e. Masukkan variabel X1 dan X2 ke Paired Variables dengan cara klik X1 lalu klik X2 dan masukkan ke kotak Paired Variables.

f. Sehingga akan muncul out put Paired Samples Statistics, Paired Samples Correlations, Paired Samples Test.

Rumus perhitungan Uji paired sample T-Test (Arikunto, 2002) : 
Ho $=$ Tidak ada perbedaan rata-rata luas guna lahan sebelum dan sesudah. $\mathrm{H}_{1}=$ Ada perbedaan rata-rata luas guna lahan sebelum dan sesudah.

Jika T hitung > T tabel, maka Ho di tolak. Jika $\mathrm{T}$ hitung $<\mathrm{T}$ tabel, maka Ho di terima.

\section{HASIL DAN PEMBAHASAN}

\section{1) Analisis Uji Paired Sample T-Test Dengan} SPSS Statistics 23 For Windows.

Analisis Uji Paired Sample T-Test Dengan SPSS Statistics 23 For Windows ini adalah metode untuk mengidentifikasi pengaruh keberadaan pembangunan Mall Tunjungan Plaza terhadap perkembangan tata guna lahan di Kelurahan Kedungdoro, dimana metode ini merupakan analisis dengan melibatkan dua pengukuran pada subyek yang sama terhadap suatu pengaruh tertentu.

Input data dilakukan pada variabel view melalui penggunaan dua variabel data yang ada, data yang digunakan adalah data hasil analisis luas penggunaan lahan masing-masing sampel sebelum pada tahun 1980 dan sesudah pada tahun 2018, berdirinya bangunan Mall Tunjungan Plaza. Adapun data yang akan di input pada Program SPSS dapat dilihat pada Tabel 1. berikut ini.

Tabel 1. Data Tata Guna Lahan Sebelum dan Sesudah pembangunan Mall Tunjungan Plaza

\begin{tabular}{cc}
\hline $\begin{array}{c}\text { Sebelum Pembangunan } \\
\text { Tahun 1980 }\end{array}$ & $\begin{array}{c}\text { Sesudah Pembangunan } \\
\text { Tahun 2018 }\end{array}$ \\
\hline 12,68 & 30,14 \\
24,85 & 42,81 \\
36,31 & 0,51 \\
0,88 & 0,36 \\
0,08 & 0,18 \\
\hline
\end{tabular}

Sumber: Hasil Analisis Tahun 2018

Pedoman Pengambilan Keputusan dalam Uji Paired Sample T-Test

a) Jika nilai Sig.(2-tailed) >0,05, maka Ho ditolak dan $\mathrm{H}_{1}$ diterima

b) Jika nilai Sig.(2-tailed) $<0,05$, maka Ho diterima dan $\mathrm{H}_{1}$ ditolak

Hipotesis yang di gunakan adalah sebagai berikut:

Ho = Tidak ada perbedaan rata-rata luas guna lahan sebelum dan sesudah

$\mathrm{H}_{1}=$ Ada perbedaan rata-rata luas guna lahan sebelum dan sesudah

Pengambilan keputusan berdasarkan nilai $\mathrm{t}$ hitung, lihat kolom $\mathrm{t}$ pada adalah sebagai berikut:
Jika nilai t hitung > t tabel, maka Ho ditolak dan Hi diterima.

Jika nilai $\mathrm{t}$ hitung $<\mathrm{t}$ tabel, maka Ho diterima dan Hi ditolak.

Setelah data sudah siap maka proses selanjutnya yaitu memasukkan data atau menginput data pada program SPSS dan memulai proses analisis dengan metode Uji Paired T-Test yang menghasilkan 3 output yaitu Paired Samples Statistics, Paired Samples Correlation dan Paired Samples Test sebagai berikut. Lebih jelasnya dapat dilihat pada Tabel 2, Tabel 3 dan Tabel 4. 
Tabel 2 Paired Samples Statistics

\begin{tabular}{l|lcccc}
\hline \multicolumn{2}{|c}{} & Mean & N & Std. Deviation & Std. Eror Mean \\
\hline Pair 1 & $\begin{array}{l}\text { Sebelum } \\
\text { Pembangunan Mall }\end{array}$ & 1496,0000 & 5 & 1564,04428 & 699,46186 \\
& $\begin{array}{l}\text { Sesudah } \\
\text { Pembangunan Mall }\end{array}$ & 1480,000 & 5 & 2028,75442 & 907,28656 \\
\hline
\end{tabular}

Tabel 3 Paired Samples Correlation

\begin{tabular}{l|llll}
\hline \multicolumn{2}{|l}{} & N & Correlation & Sig. \\
\hline Pair 1 & $\begin{array}{l}\text { Sebelum } \\
\text { Pembangunan Mall } \\
\text { \& Sesudah } \\
\text { Pembangunan Mall }\end{array}$ & 5 & 0,282 & 0,646 \\
\hline Sumber: Hasil Analisis SPSS Tahun 2018 & & \\
\hline
\end{tabular}

Tabel 4 Paired Samples Test

\begin{tabular}{|c|c|c|c|c|c|c|c|c|c|}
\hline & \multicolumn{5}{|c|}{ Paired Differences } & \multirow{3}{*}{$\mathrm{t}$} & \multirow{3}{*}{ df } & \multirow{3}{*}{$\begin{array}{l}\text { Sig. } \\
\text { tailed) }\end{array}$} \\
\hline & & \multirow[t]{2}{*}{ Mean } & \multirow{2}{*}{$\begin{array}{c}\text { Std. } \\
\text { Deviation }\end{array}$} & \multirow{2}{*}{$\begin{array}{l}\text { Std. Eror } \\
\text { Mean }\end{array}$} & \multicolumn{2}{|c|}{$\begin{array}{l}95 \% \text { Confidence Interval of } \\
\text { the Difference }\end{array}$} & & & \\
\hline & & & & & Lower & Upper & & & \\
\hline $\begin{array}{c}\text { Pair } \\
1\end{array}$ & $\begin{array}{l}\text { Sebelum } \\
\text { Pembangunan } \\
\text { Mall } \\
\text { Sesudah } \\
\text { Pembangunan } \\
\text { Mall }\end{array}$ & 16,00000 & 2184,72287 & 977,03777 & - 2696,69173 & 2728,69173 & 0,016 & 4 & 0,988 \\
\hline
\end{tabular}

Sumber: Hasil Analisis SPSS Tahun 2018

Pada Tabel 4. nilai t hitung 0,016 maka dapat dipahami untuk dasar pengambilan keputusan dalam Uji Paired Sample T-Test sebagai berikut:

Terlihat bahwa pada kolom Sig(2-tailed), untuk nilai variable tersebut adalah 0,988 mempunyai angka signifikansi $>0,05$, dengan demikian Ho di tolak $\mathrm{H}_{1}$ dinyatakan diterima atau dengan kata lain hasil analisis Uji Paired Sample T-Test Kedua variabel adalah tidak signifikan.

Hasil analisis menunjukan dengan jelas bahwa pada kolom t tabel, untuk variabel data analisis penggunaan lahan sebelum dan sesudah berdirinya bangunan Mall Tunjungan Plaza Tahun 1980 dan Tahun 2018 adalah 0,016 mempunyai angka $\mathrm{t}$ tabel $<3,18245$, dengan demikian Ho dinyatakan diterima dan $\mathrm{H}_{1}$ dinyatakan ditolak. Maka dari hasil analisis ini, dapat disimpulkan bahwa tidak ada pengaruh dampak risiko yang signifikan antara hasil data perkembangan keseimbangan penggunanaan lahan Tahun 1980 sampai dengan Tahun 2018, sebelum dan sesudah berdirinya kawasan Mall 
Wahyu Dwi Fintarto dan Moch. Shofwan : Dampak Risiko Pembangunan Mall Tunjungan Plaza Terhadap Keseimbangan Tata Guna Lahan

Tunjungan Plaza terhadap ruang permukiman di Kelurahan Kedungdoro Kota Surabaya.

\section{KESIMPULAN}

Setelah melakukan kegiatan analisis spasial perkembangan penggunaan lahan dan analisis Uji Korelasi Paired Sample T-Test dengan SPSS For Windows, dengan melibatkan dua pengukuran pada subyek yang sama antara hasil data perkembangan penggunanaan lahan Tahun 1980 dan Tahun 2018 di Kelurahan Kedungdoro, maka dapat disimpulkan bahwa tidak ada pengaruh yang signifikan, antara hasil data perkembangan keseimbangan penggunanaan lahan Tahun 1980 sampai dengan Tahun 2018, sebelum dan sesudah berdirinya kawasan Mall Tunjungan Plaza terhadap ruang permukiman di Kelurahan Kedungdoro Kota Surabaya.

\section{UCAPAN TERIMAKASIH}

Ucapan terimakasih dan penghargaan perlu disampaikan kepada berbagai pihak yang telah memberikan bantuan berupa bimbingan, arahan, saran, dukungan dan kemudahan sejak awal sampai akhir penyusunan penelitian di antaranya adalah pemerintahan Kota Surabaya yang telah mengizinkan penulis melakukan penelitian di Kota Surabaya tepatnya di Kelurahan Kedungdoro Kecamatan Tegalsari Kota Surabaya dan Program Studi Perencanaan Wilayah Kota Fakultas Teknik Sipil dan Perencanaan Universitas PGRI Adi Buana Surabaya.

\section{DAFTAR PUSTAKA}

Anonim. 2016. Kecamatan Tegalsari Dalam Angka 2017. Surabaya: Badan Pusat Statistik. Arikunto, S. 2002. Prosedur Penelitian Suatu Pendekatan Praktik. Yogyakarta: Rineka Cipta Jacon, J. 2017. Tunjungan Plaza.Wikipedia. https://id.m.wikipedia.org/wiki/Tunjungan_Plaza. Muhson, A. 2012. Pelatihan Analisis Statistik dengan SPSS. Yogjakarta: Universitas Negeri Yogyakarta. Sugiono. 2013. Metode Penelitian Kuantitatif Kualitatif Dan R\&D. Bandung: Cv. Albeta.

Peraturan Perundang-undangan

Peraturan Daerah Kota Surabaya Nomor 12 Tahun 2014 Tentang Tata Ruang Wilayah Kota Surabaya Tahun 2014-2034. 